\title{
Analysis on External Factors of the Combination of Aesthetics and Functions of the Li Nationality
}

\author{
Zheng $\mathrm{Hu}$ \\ School of Art and Fashion, Tianjin Polytechnic University \\ Tianjin 300387, China \\ Dong Xu \\ School of Art and Fashion, Tianjin Polytechnic University \\ Tianjin 300387, China \\ E-mail: tjxudong@163.com
}

\begin{abstract}
The Li nationality costume not only has practical value, but also has very high aesthetic value. In the long historical process, $\mathrm{Li}$ ethnic costume has experienced a long development and evolution process, which embodies inevitable trend of our times. The Li nationality costume expresses that the Li people advocate the aesthetic meanings of nature, history, and life of the body. It has a lot of symbolism meanings and contains many connotations that could not be explained now. This paper conducts an in-depth analysis about some external factors of the origin and development of $\mathrm{Li}$ nationality costume, including geography environment, production technology and foreign cultures. By combining modern costume design, this paper points out the meanings of inheriting and carrying forward traditional costume culture.
\end{abstract}

Keywords: Li nationality costume, Aesthetic, Function, Inheriting

According to the recordation of literatures, the Li's ancestors had been living on Hainan Island as far as Zhou and Qin period. With the long term of multiply, migration and development, the Li nationality has formed 5 dialect groups and is divided into five Li nationality branches accordingly. They are "Xiao", Qi, Sai, Run and Meifu.

The five Li nationality branches all have colorful nationality culture characteristics and costume is the most distinguished characteristic. Although the costumes of the five branches differ from each other, their outline features are common. The colors for the upper women costumes are basically black and blue. The upper woman and man's costumes are cut out of plain and linear skill, have no collar and fastener and are of two fronts or of head-through style. The lower woman costume is linear cutting-out canister skirt with knitted followers. The canister skirt is made up of waist elastic belt, skirt waist, skirt body and skirt tail, which are all made of knitted cotton. The lower man costume is "Diaochan", which is made of one cloth. The part of the costume under the waist is usually decorated with a large amount of embroiders or jacquard stripes, whose colors and knitting and painting textures are fabulous.

The Li nationality costume not only has practical values, but also has high aesthetic values. The shapes and materials not only have to be in harmony with the production and life of the Li people, but also have to adjust to the natural environment of Hanna Island, fit for their nationality spirit and personalities, and adapt to foreign cultures. Therefore, the pattern and structural features of the Li nationality costume are greatly influenced by the following factors.

\section{Geography Environment}

Hainan Island locates in tropic zones, and has sufficient lights and rains. In ancient times, Hainan Island was teemed with rivers and forests and had a lot of wild animals and plants resources. The ancient Run Li people wore bark cloth and hats. Some even could make bark cloth. It is the original costume feature of ancient Li people who were then living in mountainous areas.

Due to the wet and hot climate environment of Hainan Island, the costume of the Li nationality must be convenient and 
heat dispelling. Therefore, the Li people like to wear head-through garments and be barefoot. The head-through upper costume is easy for cutting. It only needs to cut a line shaped collar in the middle of a large cloth. Such costume is of long sleeve and with no collar. It is bounty and short with no waist. When getting dressed, people could just put on through their heads. It is like the round collar shirt that we wear today (please refer to picture 1). Although it looks to be bounty and thick, actually it breathes freely and absorbs sweat. Men usually wear short upper clothes and genitals covering cloth, which is also named "Diaochan". "Diaochan" is made of two cloths to cover men's genitals, which looks like the present briefs (please refer to picture 2).

When working, men would be barebacked. Their clothing became obstacles to dispel heat. However, genitals covering cloth could reduce the clothing to the minimum degree, which is convenient for them to work under hot weather. Women liked to wear canister skirt of glory color and beautiful embroidery.

The length of canister skirt varies. Women along coast areas and plain areas would wear long canister skirt, such as Sai $\mathrm{Li}$ and Meifu Li women. Meifu Li women, in Dongfang and Changjiang areas, wear the longest canister skirt. Their skirt is as long as 155 centimeters, which is called as "long canister skirt". Because there are a lot of gullies, springs and rivers, in mountainous areas, women would wear middle-long or short skirt for the convenience of work, such as Xiao $\mathrm{Li}$ and Run Li. The skirt wore by Run Li women in Baisha county is the shortest, about 30 centimeters long, with the shortest to be only 24 centimeters.

\section{Production technology}

The weather of Hainan Island is very hot and land there is fertile and is alkali, which is suitable for the growth of ceiba and hemp. Before the popularity of cotton, hemp textile was very popular in Li nationality area. Hemp is solid and is mostly used to make coat and under clothing. The ancient Yazhou (Sanya city today) was rich in the production of cotton. According to the record of historical books, the traditional cotton weaving techniques in Li nationality has a history of more than 2000 years. According to the record of Post-Han Book, "as wide as 166 centimeters and is as white as snow". It shows that the weaving technology of Li nationality at that time achieved very high level.

The spinning, twining, painting and embroidering of Li nationality all have special features. What is more, Li people have created various twining, painting and embroidering skills according to their preferences, among which the baldachin technique is the most famous. The Li people utilized various weaving tools to gin, spring cotton, spin lines, paint colors, tidy up texture, weave and embroider. They could make colorful baldachin, decoration cloth, embroidery piece, and canister skirt and flower band. All these things are made in elegant style and are very beautiful and practical. The Li people have formed their distinguished production technique. The brocade of Li nationality has various styles. Some are simple and unsophisticated, some are elegant and grand, and some are light. Because the flower weaving clothe is dense in latitude and longitude, which enhances the solidarity of the costume and enriches the costume's features. Hence, they are very popular.

The twining machines used by Li nationality to weave cotton are mainly foot-stepping twining machines and Juyao twining machines. Juyao twining machine is a old twining machine, which is similar to the machine used by Banpo clan six or seven thousand years ago. With Juyao twining machine, Li nationality women could make elegant and complicated pictures. Their jacquard technology is even better than modern jacquard equipments. However, because the cloth made is narrow, they are more suitable for decorating part of the costume or edges. Therefore, to use pieces to make up a costume becomes a characteristic of Li nationality costume.

Firstly, pieces are more complicated than traditional head-through costume. Let us take typical Qi Li and Run Li women's costume as an example. Please refer to picture 3. The upper clothing of Qi Li women is open front. A horizontal line under the breast divides the front. Below the dividing line, square embroidery piece is used to decorate it. In the front of Run Li head-through costume, there are two vertical dividing lines, which divide the front into three sections. The square pieces below the dividing line are decorated with embroidery. The square of the embroidery is smaller than Qi Li women's costume. The lower edge of the middle part and the wristband are embroidered with two direction continuous pictures. The length and width of the pieces are proportional and the division arrangements of the pieces are balanced and symmetrical. Please refer to picture 4 .

Secondly, because of the augment of pieces, the dividing lines among pieces increase. In order not to influence the beauty sense, Li nationality women would decorate the pieces with flower chiffons. Or they would embroider gridding pattern onto the dividing lines. By this way, such dividing lines become decoration lines and change disadvantages into advantages and change the nature of the joint lines.

\section{Traditional culture}

in the long historical process, the social productivity of Li nationality was restrained by economy conditions and developed slowly. In vast areas, the Li nationality stagnated in clan community system stage for a long time. In Wuzhi Mountain hillside, the Li nationality even kept clan community system to 1950 s. 
The Li nationality life style based on clan system economy passed down from generation to generation and formed special national culture psychological accumulation. In the totally occlusive mountainside life, a recognition style of one-way intuitive thinking pattern was formed. Therefore, Li nationality tradition culture is one kind of national culture of natural form and has primitive and honest culture particularity, which is shown in costume culture as the worship of ancestor and revering to all things on earth.

The patterns on the Li nationality women's clothing describe the various phenomenon in their life, physical labor and natural world, such as the sun, the moon and stars, thunder, lightning, rainbow, birds and beasts, flowers, plants, fishes and insects. Jacquard patterns on clothing materials are mostly personages, streetscapes, animals, plants, geometry shapes and etc. Also, seeing from the formation style of patterns, the knitting pattern of Li nationality costumes is usually continuous patterns, that are two-direction continuity and four-direction continuity. In Li nationality costume, no matter in knitting flower canister skirt or in neckline, wristband or front, the most popular patterns arrangement forms are two-direction continuous plain arrangement. The patterns on the canister are repetitive two-direction pattern arrangement. Hence, it has strong sense of rhythm and order. The patterns and colors of Li nationality costumes, through subtle combination of the dots, lines, faces and colors, enables us to feel three dimension or multi-dimension space sense from two dimension plain. Please refer to picture 5.

Run Li costume in Baosha county is original. Women coil up their hair and wear blue head-through clothing. Their clothing side and wristband are embroidered with elaborate two-faced embroidery. They would wear Li short canister skirt and are used to be bear-foot. Traditional men would wear no collar symmetrical front clothing and Diaochan. They also would be bear-foot with a handkerchief covering their head. There is some embroidery on their clothing. The Qi Li in Qionghebaoting area is good at knitting. Their canister skirt and head handkerchief are made of fancy Li cotton. Women would wear no collar symmetrical front coat, canister skirt, canister head handkerchief, and like to wear various silver decorations. Men would wear no collar symmetrical coat and large Diaochan. Xiao Li women in Ledong county would wear symmetrical open breast coat with not fastener. Collar front and back will be decorated with embroidery. They would also wear blue strip canister skirt. Traditional men costume is strip symmetrical front long coat with not fasteners. They will wear genitals covering cloth. A feather will be put on their heads. Meifu Li women from Dongfang County would wear big collar symmetrical front coat and painted knitting long canister skirt. They would coil up their long hair all behind their head and wear black and white strip head handkerchief. Men would wear big collar symmetrical front coat, which is looser than women's. They would wear knee cover skirt and timber shoes and large bamboo hat. Sai Li women from Baoting County would wear straight collar big front coat with narrow sleeve and tight shape. They would also wear knitted flower long canister skirt and flower shoes. They also like to wear various silver decorations.

Usually, Li nationality women would wear black symmetrical front coat and painted flower canister skirt. However, in festivals and special occasions, they will wear grand clothing. Besides decoration textures, Li nationality women would also embroider and sew gold and silver foil, feathers, shells, pearls, copper lines or edging onto their clothing. With the accouterment, those clothing is jewelly, glittering and grand.

In addition, Li nationality would invite "ghost uncle" to make sacrifice. When making sacrifice, the "ghost uncle", also called as "third uncle", would dress differently. For example, when the "third uncle" of Meifu dialect made sacrifice, he would dress a long coat with open breast, long sleeves and cloth fasteners. The long coat reaches below the ankles. A earth red band is used to tie the waist. The collar is sewed with 8 to 10 centimeters band. Its color is gentle. He will also wear flower hat with a peasant circus on the hat. Also, he will wear copper chaplet and bracelet to keep away the ghosts.

\section{Foreign culture}

The Li nationality originated from Luoyue. In the long development of culture, foreign cultures, including Han culture, Zhuang culture and local short black people culture, constantly become integrated into Li culture. Han culture exerted a deep influence on Li culture.

In the long history, the people of Li nationality in Han dynasty lived all over of Hainan Island. In Tang dynasty, Han people occupied the north and Li the south. In Song and Yuan period, feudal kingdom enhanced their control over Li people. And Li nationality was forced to move back to Wuzhi Mountain area and then a pattern was formed where Han people was at the outer and $\mathrm{Li}$ in the middle. The Han culture is advanced and strong and exerted influence on various factors of Li culture. However, some of Li cultures were also recognized and accepted by Han culture and hence, a mixed culture is formed.

Since Tang dynasty, it has been recorded that people from the middle plain moved to Hainan Island out of various reasons and became integrated into Li nationality. Up to Ming dynasty, with the further development of feudal economy, more and more Han people moved to Li area. Many of them permanently lived in $\mathrm{Li}$ area and become member of $\mathrm{Li}$ nationality.

In the process of the mutual penetration of Han and Li culture, the costume structure of Li nationality is changing 
gradually. The most obvious is to change the no collar and straight pocket and head-through upper clothes to digging pocket and collar. They also change straight body, straight sewing and straight sleeves to waist body, suture and pucker at wristband. Also, they change no fastener to decorating fasteners or lute fasteners. Finally, they change symmetry front into leaning front.

For example, the women costume of Sai Li nationality, the upper clothes are mostly blue or deep blue. Old women mostly wear black cloth with long sleeve and high collar. The front of cloths is decorated with cloth fasteners of different distance and is very similar to cheong-sam.

The man's costume of Run Li nationality was earlier influenced by Han nationality and hence, they more wear Han costumes. However, when making sacrifice, their clothes are embroidery clothes that have Li nationality features and are made according to Han costume. They buy cloth that are of traditional styles of Li nationality and add them onto the Han costumes from Han merchants.

With the evolution of times and the rapid development of modern cities, more and more Li nationality youth go out of mountains and study and work in economy-developed areas where Han nationality stay. They only wear their traditional Li nationality costume in big festival and significant events.

\section{Thoughts on culture inheriting}

The Li nationality costume is both a symbol of their nationality and is also a symbol of their nationality's culture. Being the same as other craftworks, the emergence of it is due to the demands of functions. The first one is practical function, which is to cover body and keep warm for the body. And then it comes the symbolization meanings and cultural connotations. At the same time, costume should also have high aesthetic taste in art, which is to mead people's aesthetic spiritual demands.

The Li nationality costume has experienced a long development and evolution process and embodies the inevitable trend of times. The Li nationality costume expresses that the Li peoples advocate the aesthetic meanings of nature, history, and life of the body. It has a lot of symbolism meanings and contains many connotations that could not be explained now.

When modern people measure their aesthetic styles with aesthetic principles, they find that the shapes and colors of the Li nationality costumes both follow the common theories of beauty, including contrast and harmony, cadence and rhythm, various styles and unified styles. Their costume structures could be divided into holistic structure and sectional structure. Holistic structure refers to that the outline structure of costume is the style formed by the outline of the costume and is also the theme of the costume style, which is of significance functions to the outlook of the costume.

The traditional spinning, painting, kitting and embroider of the Li nationality has thousands of years history. Their techniques, the original forms of materials as well as the original zoology they express have become the living cultural fossil for human society. The knitting cotton is made by hands and uses colors daintily. The designs and patterns of the Li nationality costume become special character signs and record the history and culture of the Li nationality. The double-faced embroidery technique, single-faced flower knitting technique and traditional painting technique have been included into "National non-materials culture legacy magnum opus works list" and attract people's attention. More and more local costume designers start to explore the artistic values of their nationality's elements. However, it is a long and hard task to realize the combination of nationality characteristics with modernization and inherit and carry forward the cultural elite of the Li nationality's traditional costumes.

\section{References}

Wang, Guoquan. (1985). The Li Nationality Amorous Feelings.

Wang, Xueping. (2004). The Li Nationality of China. Bejing: Minzu Press.

Wang, Yangmin. (1993). A Probe into the Li Nationality Culture. Guilin: Guangxi Nationality Press.

Xing, Guanying. (1990). The Li Nationality.

Xing, Zhichao. (1993). The Source of the Li Nationality Culture. 


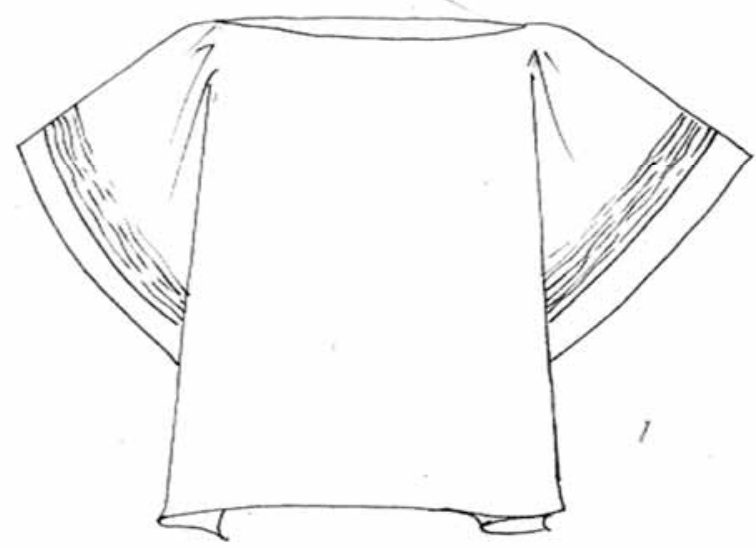

Picture 1.

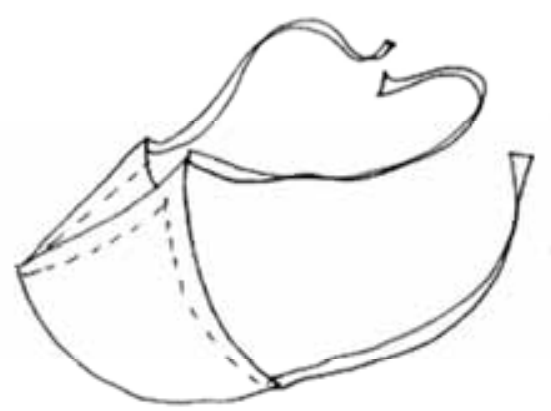

Picture 2. 


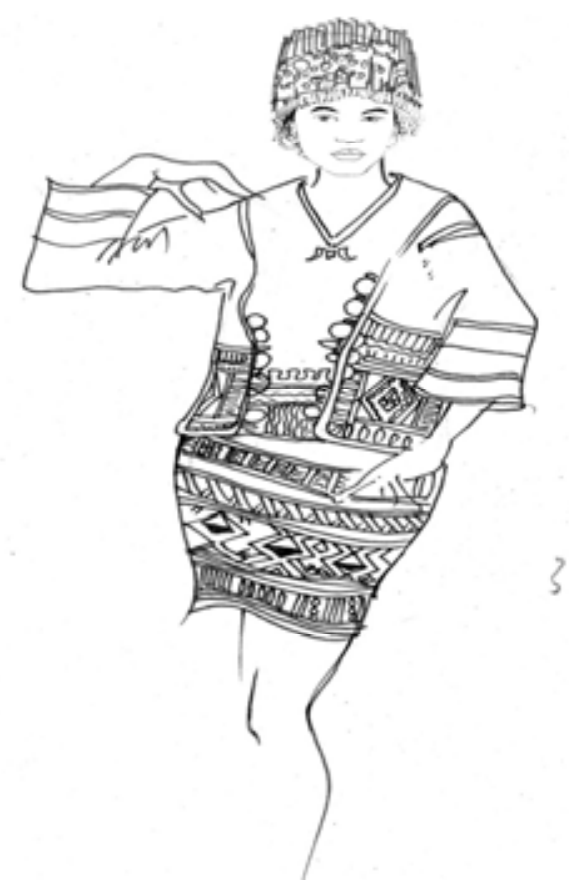

Picture 3.

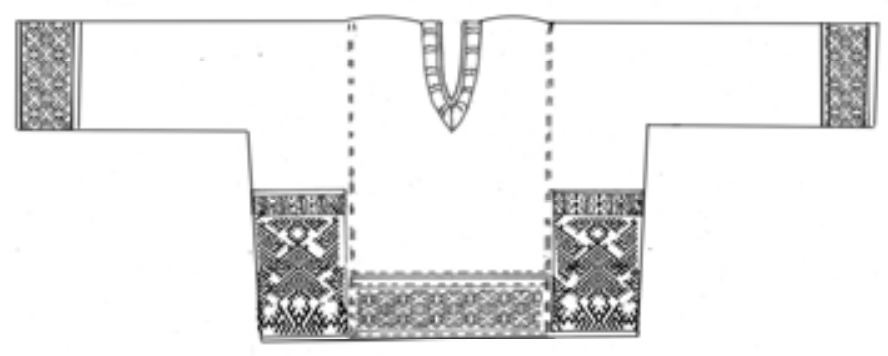

Picture 4. 

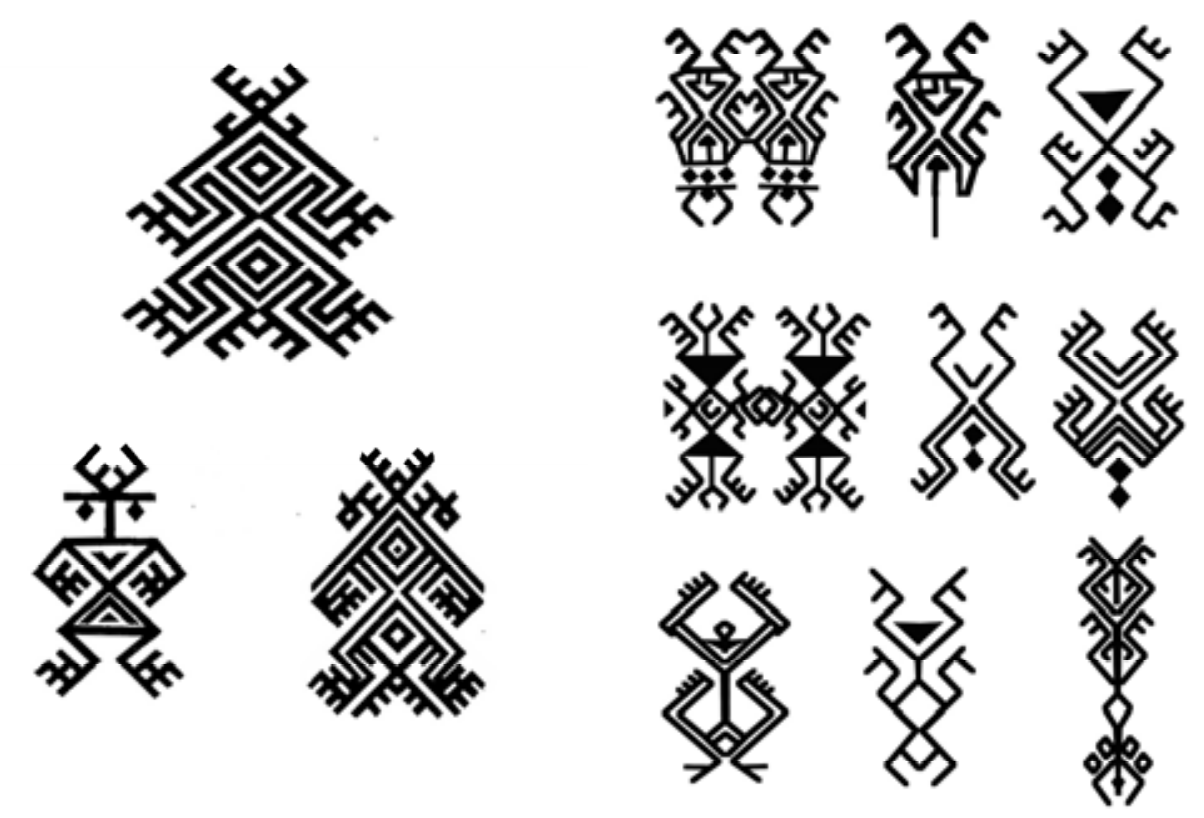

Picture 5. 